\section{LUPUS SCIENCE \& MEDICINE}

\title{
Hospitalisation for systemic lupus erythematosus associates with an increased risk of mortality in Australian patients from 1980 to 2014: a longitudinal, population-level, data linkage, cohort study
}

\author{
Warren David Raymond (10 , ${ }^{1}$ Susan Lester, ${ }^{2}$ David Brian Preen, ${ }^{3}$ \\ Helen Isobel Keen, ${ }^{4}$ Charles Anoopkumar Inderjeeth, ${ }^{1,5}$ Michael Furfaro, ${ }^{1}$ \\ Johannes Cornelis Nossent (iD) 1,5
}

To cite: Raymond WD, Lester S, Preen DB, et al. Hospitalisation for systemic lupus

erythematosus associates with an increased risk of mortality in Australian patients from 1980 to 2014: a longitudinal, populationlevel, data linkage, cohort study. Lupus Science \& Medicine 2021;8:e000539. doi:10.1136/ lupus-2021-000539

- Additional supplemental material is published online only. To view, please visit the journal online (http://dx.doi.org/10. 1136/lupus-2021-000539).

Received 16 July 2021 Accepted 26 September 2021

Check for updates

(C) Author(s) (or their employer(s)) 2021. Re-use permitted under CC BY-NC. No commercial re-use. See rights and permissions. Published by BMJ.

For numbered affiliations see end of article.

Correspondence to

Warren David Raymond; warren. raymond@uwa.edu.au

\section{ABSTRACT}

Objective Mortality rates for patients with SLE have not been reported in Australia. This study determined the association between a hospitalisation for SLE with mortality.

Methods Population-level cohort study of patients with SLE ( $n=2112 ; 25710$ person-years) and general population comparators (controls) ( $n=21,120 ; 280637$ person-years) identified from hospital records contained within the WA Rheumatic Disease Epidemiological Registry from 1980 to 2013. SLE was identified by ICD-9-CM: 695.4, 710.0, ICD10-AM: L93.0, M32.0. Controls were nearest matched (10:1) for age, sex, Aboriginality and temporality. Using longitudinal linked health data, we assessed the association between a hospitalisation for SLE mortality and mortality with univariate and multivariate Cox proportional hazards and competing risks regression models.

Results At timezero, patients with SLE were similar in age (43.96 years), with higher representation of females $(85.1 \%$ vs $83.4 \%, p=0.038)$, Aboriginal Australians (7.8\% vs $6.0 \%)$ and smokers (20.5\% vs $13.2 \%)$. Before study entry, patients with SLE (mean lookback 9 years) had higher comorbidity accrual (Charlson Comorbidity Index $\geq 1$ item $(42.0 \%$ vs $20.5 \%))$, especially cardiovascular disease (CVD) (44.7\% vs $21.0 \%$ ) and nephritis (16.4\% vs $0.5 \%$ ), all $p<0.001$. During follow-up (mean 12.5years), 548 (26.0\%) patients with SLE and 2450 (11.6\%) comparators died. A hospitalisation for SLE increased the unadjusted ( $\mathrm{HR} 2.42,95 \% \mathrm{Cl} 2.20$ to 2.65) and multivariate-adjusted risk of mortality (aHR $2.03,95 \% \mathrm{Cl}$ 1.84 to 2.23), which reduced from 1980 to 1999 (aHR 1.42) to 2000-2014 (aHR 1.27). Females (aHR 2.11), Aboriginal Australians (aHR 3.32), socioeconomically disadvantaged (aHR 2.49), and those $<40$ years old (aHR 7.46) were most vulnerable. At death, patients with SLE had a higher burden of infection (aHR 4.38), CVD (aHR 2.09) and renal disease (aHR 3.43), all $p<0.001$.

Conclusions A hospitalisation for SLE associated with an increased risk of mortality over the 1980-2014 period compared with the general population. The risk was especially high in younger ( $<40$ years old), socioeconomically disadvantaged and Aboriginal Australians.

\begin{tabular}{|c|c|}
\hline \multicolumn{2}{|c|}{ KEY MESSAGES } \\
\hline WHA & AT IS ALREADY KNOWN ABOUT THIS SUBJECT? \\
\hline $\begin{array}{rl}P & P \\
c \\
t \\
n \\
n\end{array}$ & $\begin{array}{l}\text { Patients with SLE experience premature mortality } \\
\text { compared with the general population. However, } \\
\text { there are no population-level studies on the risk of } \\
\text { mortality in patients with SLE in Australia, and infor- } \\
\text { mation on Aboriginal Australians with SLE is scarce. }\end{array}$ \\
\hline \multicolumn{2}{|r|}{ WHAT DOES THIS STUDY ADD? } \\
\hline & $\begin{array}{l}\text { Hospitalisation for SLE increased the risk of mor- } \\
\text { tality relative to general population comparators in } \\
\text { Western Australia from } 1980 \text { to } 2014 \text {. } \\
\text { The highest mortality risk was seen in patients with } \\
\text { SLE under } 40 \text { years of age, the socioeconomically } \\
\text { disadvantaged, and Aboriginal Australians. } \\
\text { Patients with SLE carry substantially more comor- } \\
\text { bidity at the time of hospitalisation and death com- } \\
\text { pared with general population comparators. }\end{array}$ \\
\hline $\begin{array}{l}\text { HOW } \\
\text { OR F }\end{array}$ & $\begin{array}{l}\text { N MIGHT THIS IMPACT ON CLINICAL PRACTICE } \\
\text { FUTURE DEVELOPMENTS? }\end{array}$ \\
\hline & $\begin{array}{l}\text { Beyond the attempt to manage the increased risk of } \\
\text { premature mortality after a hospitalisation for SLE, } \\
\text { clinicians should be particularly mindful about man- } \\
\text { aging comorbidity and modifiable risk factors, such } \\
\text { as smoking, alcohol consumption and obesity, to } \\
\text { improve survival in this patient population. Special } \\
\text { attention should be given to patients with SLE under } \\
40 \text { years of age, the socioeconomically disadvan- } \\
\text { taged, and Aboriginal Australians. }\end{array}$ \\
\hline
\end{tabular}

\section{INTRODUCTION}

SLE is a chronic inflammatory autoimmune disease where a variety of organ complications, which often require intensive and/ or long-term use of immunosuppressive medication, contribute to an increased risk 
of premature mortality. ${ }^{1}$ During the 10 years from 1970 to 1979 , a large multinational cohort study reported a standardised mortality rate (SMR) of 4.9 for patients with SLE compared with the general population. ${ }^{2}$ A 2014 meta-analysis showed that the increased meta-SMR for patients with SLE compared with the general population had reduced, but remained elevated (meta-SMR of 3). ${ }^{3}$ Recent data from the UK demonstrated that this lifeexpectancy gap had improved for patients with SLE, up until 2000, but the overall increased risk of mortality was unchanged thereafter to $2014 .^{45}$

Australian data on mortality in SLE are limited to singlecentred, retrospective studies of high-risk groups. ${ }^{6-8}$ These studies showed increased mortality among those with lupus nephritis, ${ }^{9}$ as well as Aboriginal Australians treated in either metropolitan $(n=6)$ or regional centres, including the Northern Territory of Australia ( $n=22$; mortality rate (MR) 90.4) and Central Australia ( $n=18$; MR 18). ${ }^{81011}$ This is the first Australian study, using wholepopulation longitudinal linked health data, to investigate all-cause mortality and the underlying and contributing causes of death in a cohort of patients with SLE from 1980 to 2014 .

\section{METHODS}

This whole-of-population cohort study used data linked by the Western Australian Data Linkage System, which uses probabilistic matching (99.7\% accuracy) to identify individuals across administrative health datasets. ${ }^{12}$ The Western Australian Rheumatic Disease Epidemiological Registry (WARDER) includes all private and public hospital separations (emergency department presentations, inpatient episodes, including same-day interventions and admissions, as well as cancer notifications and death notifications) statewide for over 200000 patients with rheumatic disease conditions and another 200000 non-exposed general population comparators (free from the conditions defined in online supplemental table 1). The WARDER comprises information linked from the Hospital Morbidity Data Collection (HMDC, from 1970), WA Cancer Registry (from 1982) and the Death Register (from 1969) and the Emergency Department Data Collection (from 2002). Since the 1970s, the HMDC has recorded the primary and (up to 20) co-diagnoses and the primary and (up to 10) secondary procedure codes for each hospital-level in-patient separation using the International Statistical Classification of Diseases and Related Health Problems (ICD) 9th, ${ }^{13}{ }^{14}$ ICD 10th revision ${ }^{15}$ or the Australian Classification of Health Interventions codes. ${ }^{16}$ The linkage of the WARDER dataset was done on 1 February 2017.

Within participants of the WARDER, aged 0-80 years, hospitalisations for SLE were identified in the HMDC between 1 January 1980 and 31 December 2013 by ICD9-CM: 695.4 and 710.0, and ICD-10-AM: M32.0, M32.1, M32.8, M32.9, L93.0, L93.1 and L93.2. In 2013, Ward reported that administrative data were valid in the identification of rare diseases and suitable for producing epidemiological estimates. ${ }^{17}$ In addition, in administrative or claims data, having at least one ICD-9-CM code of SLE (ICD-9: 694.4 and 710) had a positive predictive value of $70 \%-96 \%{ }^{18}$ Internationally, $89 \%$ to $93 \%$ of patients with SLE meeting classification criteria are hospitalised during their disease course. ${ }^{19}{ }^{20}$ Given that the HMDC captures same-day drug infusions (although not the specific drug types) and procedures, at a minimum our cohort would represent patients with SLE with moderate-to-severe disease.

Patients with SLE $(\mathrm{n}=2111)$ were propensity score matched (1:10) to 22110 controls free of rheumatic disease conditions. Timezero (study entry) was defined as the index hospitalisation for SLE and a random hospitalisation in the non-exposed comparators. Patients with SLE and controls were matched for the year of the index (first ever) hospital contact, year of timezero, age at timezero, gender and Aboriginality. Aboriginality, captured via self-identification during hospital admissions, is over $90 \%$ accurate; thus, to reduce the likelihood of under-reporting, we defined Aboriginality as the presence of an 'Aboriginality' flag being present for at least $25 \%$ of all hospital admissions since 1980. Socioeconomic status was proxied using the Socio-economic Indices for Areas (SEIFA)-Index of Relative Socio-Economic Advantage and Disadvantage (IRSAD).$^{21}$ Available for hospitalisation since 2006, IRSAD scores are calculated from 5-yearly census data and then divided into quintiles based on residential postcode (quintile 1 -most disadvantaged through to quintile 5 - most advantaged). ${ }^{21}$ Comorbidities, modifiable risk factors (smoking, harmful alcohol use and obesity) and intravenous/intramuscular corticosteroid administration were identified in the HMDC with the ICD codes defined in online supplemental table 2.

All-cause and cause-specific mortality was determined from the Death Register which contains demographic information related to the individual and coded death certificate data using information in Parts 1 and 2 of the death certificate, or all diagnosis text fields from the death certificate. The Death Register data included the contributing causes of death data from 1980. ICD codes were used for diagnoses in the HMDC and contributing causes of death in the WA Death registry. Contributing causes of death were defined according to the Australian Institute of Health and Welfare's Multiple causes of death: An analysis of all natural and selected chronic disease causes of death 1997-2007, and further defined based on the most prevalent diseases per category. ${ }^{22}$

\section{Statistical analysis}

Results are presented as a mean with SD, median with $\mathrm{IQR}$ or frequency and proportion. Between-group differences were assessed with the t-test, Mann-Whitney U test, $\chi^{2}$ test and ORs with 95\% CIs as appropriate. To mitigate the likelihood of incurring an immortal time bias, a maximum of 20 person-years were calculated from timezero to the date of the death event or relevant exit 
date, for example, 31 December 2014. We determined the association between a hospitalisation for SLE and 20-year all-cause mortality with univariate and multivariate Cox proportional hazards regression models. Sub-group and period-specific (overall, 1980-1999 and 2000-2014) analysis looked at the association between a hospitalisation for SLE and 20-year mortality within, males, non-Indigenous Australians, Aboriginal Australians, age groups $(<40$, $40-49,50-59,60-69$ and $\geq 70$ years of age) and socioeconomic status (quintiles). The association between a hospitalisation for SLE and 1-year, 3-year, and 5-year risk of mortality was also conducted. A multiple causes of death analysis was done with competing risks regression to determine the burden of contributing causes of death. ${ }^{22}$ The multivariate models for overall mortality risk were adjusted for age, ${ }^{2}$ gender, Aboriginality, prevalent number of Charlson Comorbidity Items $(0=$ no CCI items, $1=1-2$ CGI items, $2=3$ or more CGI items) ${ }^{23}$ Period-specific multivariate models were adjusted for age, age, ${ }^{2}$ gender, Aboriginality and CCI categories. No significant interactions were found in an effect modification analysis of prevalent clinical thromboembolic events, alcohol consumption, smoking, obesity, prevalent hypothyroidism, prevalent hypertension, prevalent diabetes, dyslipidaemia and the requirement of intravenous/intramuscular (IV/IM) corticosteroids ever, all $\mathrm{p}>0.10$. Within patients with SLE, we assessed whether the risk of mortality was higher in sub-groups with prevalent thromboembolic events, other rheumatic diseases and nephritis. Direct standardisation included the calculation of standardised mortality rates (SMRs) using the reference population data from the 2011 Census data for WA from the Australian Bureau of Statistics. ${ }^{24}$ Expected deaths were estimated at yearly intervals using the Stata strs ado program and the Ederer II method. ${ }^{25}$ The statistical analysis including Cox proportional hazards, competing risks regression and the direct standardisation was done using Stata V.16.1.

\section{RESULTS}

Patients hospitalised for SLE were similar for age (43.96 years) and socioeconomic status, with a marginally higher representation of $(85.1 \%$ vs $83.4 \%$ female, $\mathrm{p}=0.038)$ and Aboriginal Australians (OR 1.32, 95\% CI 1.11 to 1.56). Those hospitalised for SLE were more likely to have any CCI item (OR 2.81, 95\% CI 2.56 to 3.08), but had equivalent median CCI scores (2 vs $2, \mathrm{p}=0.160$ ) as well as higher odds of having thromboembolic events, hypertension, dyslipidaemia, hypothyroidism, and nephritis and proteinuria. Patients with SLE were more likely to have a history of harmful alcohol consumption, smoking and obesity (table 1).

\section{Association between a hospitalisation for SLE with the risk of mortality}

A total of 548 (26.0\%) deaths occurred in the SLE cohort compared with 2450 in controls $(11.6 \%)$. At the time of death, patients with SLE were on average 11.5 years younger (64.6 vs 76.05 years, $p<0.001$ ), died earlier after hospitalisation (6.85 vs 7.43 years of follow-up, $\mathrm{p}<0.001$ ), and were more likely to die in hospital $(71.5 \%$ vs $55.0 \%$, $\mathrm{p}<0.001)$ or on arrival to hospital $(1.1 \%$ vs $0.9 \%, \mathrm{p}<0.001)$ (figure 1). Overall, a hospitalisation for SLE associated with an increased risk of all-cause mortality compared with general population comparators in the unadjusted (HR 2.42, 95\% CI 2.20 to 2.65; $\mathrm{p}<0.001$ ) and multivariateadjusted (aHR 2.03, 95\% CI 1.84 to 2.23; $\mathrm{p}<0.001$ ) models from 1980 to 2014. This increased risk of mortality following a hospitalisation for SLE was seen in the 19801999 period (aHR $1.42,95 \%$ CI 1.20 to 1.70 ; $\mathrm{p}<0.001$ ), and while reduced in the 2000-2014 period, it remained higher than the comparators (aHR 1.27, 95\% CI 1.11 to $1.45 ; \mathrm{p}<0.001$ ) (table 2).

Relative to comparators, a hospitalisation for SLE associated with a higher risk of all-cause mortality in female rather than male patients. Furthermore, in the 1980-1999 period, a hospitalisation for male SLE was not associated with survival (aHR 1.07, 95\% CI 0.76 to 1.51 ; $\mathrm{p}=0.697$ ). Aboriginal Australians hospitalised for SLE had substantially higher (age-adjusted and sex-adjusted) risk of mortality throughout the study period; however, this association was attenuated in the fully adjusted modelling. While significant improvements were seen across the 1980-1999 (aHR 4.65) to 2000-2014 (aHR 2.63) period, Aboriginal Australians hospitalised for SLE remained among the most vulnerable patients, although this was due to a greater influence of comorbidity and modifiable risk factors on premature mortality. While patients with SLE had increased risk of mortality across all age groups, the risk was especially high in patients under 40 years of age. In addition, we demonstrated that SLE associated with a high risk of mortality within 1 to 5 years post-hospitalisation. Furthermore, a hospitalisation for SLE associated with an increased risk of mortality across all socioeconomic quintiles, with the highest risk seen in those at the most disadvantage (Q1: aHR 2.49) (table 2).

Effect modification of the association between a hospitalisation for SLE and the risk of mortality was evident for prevalent thromboembolic events, harmful alcohol use, smoking status, hypertension, hypothyroidism, dyslipidaemia, diabetes and IV/IM corticosteroid requirement, but not obesity (table 3 ).

Within hospitalised patients with SLE, prevalent hospitalisation for another rheumatic disease, antiphospholipid syndrome (ever) or thromboembolic events had no influence on survival. Yet, those hospitalised for nephritis and/or haemato-proteinuria during the lookback period increased the risk of all-cause mortality (aHR 1.43, 95\% CI 1.13 to $1.80 ; \mathrm{p}=0.004$ ) (online supplemental table 3$)$.

\section{Direct standardisation}

Hospital-based comparators had similar survival compared with the estimated resident population of Western Australia in 2011 ${ }^{24}$ (figure 2A). Compared with the background population of Western Australia, patients with SLE had an increased age-adjusted and sex-adjusted standardised mortality rate ratio (SMR) from 1980 to 2014 
Table 1 Cohort characteristics at study entry

\begin{tabular}{|c|c|c|c|}
\hline & SLE & Comparators & OR $(95 \% \mathrm{Cl})$ \\
\hline Participants, $n$ & 2111 & 21110 & \\
\hline Lookback time, mean \pm SD & $9.25 \pm 8.57$ & $9.03 \pm 9.42$ & - \\
\hline Follow-up time, mean $\pm S D$ & $13.69 \pm 9.10$ & $16.00 \pm 10.12$ & - \\
\hline \multicolumn{4}{|l|}{ Demographics } \\
\hline Age, mean $\pm S D$ & $43.96 \pm 17.74$ & $43.54 \pm 19.65$ & - \\
\hline Males, n (\%) & $314(14.9)$ & $3512(16.6)$ & - \\
\hline Females, n (\%) & $1797(85.1)$ & $17598(83.4)$ & - \\
\hline Aboriginality, n (\%) & $165(7.8)$ & $1275(6.0)$ & $1.32(1.11$ to 1.56$)$ \\
\hline SEIFA (IRSAD) quintiles, $n=$ data available & 1595 & 17051 & \\
\hline Quintile 1-most disadvantaged, n (\%) & $206(12.9)$ & $2045(12.0)$ & Reference \\
\hline Quintile 2, n (\%) & $204(12.8)$ & $2411(14.1)$ & 0.84 (0.69 to 1.03$)$ \\
\hline Quintile 3, n (\%) & $282(17.7)$ & $3055(17.9)$ & $0.92(0.76$ to 1.11$)$ \\
\hline Quintile 4, n (\%) & $472(29.6)$ & $5050(29.6)$ & $0.93(0.78$ to 1.10$)$ \\
\hline Quintile 5-most advantaged, n (\%) & $431(27.0)$ & $4490(26.3)$ & 0.95 (0.80 to 1.13$)$ \\
\hline \multicolumn{4}{|l|}{ Modifiable risk factors } \\
\hline Harmful alcohol use, n (\%) & $83(3.9)$ & $467(2.2)$ & $1.81(1.43$ to 2.30$)$ \\
\hline Obesity, n (\%) & $133(6.3)$ & $604(2.9)$ & 2.28 (1.88 to 2.77$)$ \\
\hline Smoking status, n (\%) & $432(20.5)$ & $2782(13.2)$ & $1.70(1.51$ to 1.90$)$ \\
\hline \multicolumn{4}{|l|}{ Comorbidity at timezero } \\
\hline Cardiovascular disease, $\mathrm{n}(\%)$ & $943(44.7)$ & $4425(21.0)$ & 3.04 (2.78 to 3.34$)$ \\
\hline Acute myocardial infarction, n (\%) & $78(3.7)$ & $416(2.0)$ & 1.91 (1.49 to 2.44$)$ \\
\hline Congestive heart failure, $\mathrm{n}(\%)$ & $119(5.6)$ & $339(1.6)$ & 3.66 (2.96 to 4.53$)$ \\
\hline Thromboembolic events, n (\%) & $245(11.6)$ & $498(2.4)$ & $3.87(2.64$ to 5.66$)$ \\
\hline Peripheral vascular disease, $\mathrm{n}(\%)$ & $71(3.4)$ & $196(0.9)$ & 4.08 (2.14 to 7.79$)$ \\
\hline Cerebrovascular disease, $\mathrm{n}(\%)$ & $125(5.9)$ & $427(2.0)$ & 2.81 (1.78 to 4.43$)$ \\
\hline Antiphospholipid autoantibodies ever, n (\%) & $80(3.8 \%)$ & $9(0.0 \%)$ & 92.4 (46.3 to 184.2$)$ \\
\hline Hypertension, n (\%) & $388(18.4)$ & $1743(8.3)$ & 2.50 (2.21 to 2.82$)$ \\
\hline Dyslipidaemia, n (\%) & $85(4.0)$ & $540(2.6)$ & 1.60 (1.27 to 2.02$)$ \\
\hline Dementia, n (\%) & $9(0.4)$ & $110(0.5)$ & $0.82(0.41$ to 1.62$)$ \\
\hline Chronic pulmonary disease, $\mathrm{n}(\%)$ & $277(13.1)$ & $1236(5.9)$ & 2.43 (2.11 to 2.79$)$ \\
\hline Rheumatic disease (excluding SLE), n (\%) & $211(10.0)$ & $0(0.0)$ & - \\
\hline Osteoporosis (OP), n (\%) & 41 (1.9) & $61(0.3)$ & $6.87(4.61$ to 10.23$)$ \\
\hline OP with fracture, n (\%) & $13(0.6)$ & $19(0.1)$ & 7.00 (3.45 to 14.18$)$ \\
\hline Peptic ulcer, n (\%) & $103(4.9)$ & $380(1.8)$ & $2.80(2.24$ to 3.50$)$ \\
\hline Mild liver disease, $\mathrm{n}(\%)$ & $87(4.1)$ & $193(0.9)$ & 4.66 (3.60 to 6.03$)$ \\
\hline Moderate or severe liver disease, $n$ (\%) & $16(0.8)$ & $33(0.2)$ & 4.88 (2.68 to 8.88$)$ \\
\hline Diabetes (any), n (\%) & $131(6.2)$ & $914(4.3)$ & $1.46(1.21$ to 1.77$)$ \\
\hline Diabetes without complications, $\mathrm{n}(\%)$ & $123(5.8)$ & 769 (3.6) & 1.64 (1.35 to 1.99$)$ \\
\hline Diabetes with complications, $\mathrm{n}(\%)$ & $50(2.4)$ & $392(1.9)$ & $1.28(0.95$ to 1.73$)$ \\
\hline Hypothyroidism, n (\%) & $90(4.3)$ & $199(0.9)$ & 4.68 (3.63 to 6.03$)$ \\
\hline Hemi/paraplegia, n (\%) & $49(2.3)$ & $166(0.8)$ & $3.00(2.17$ to 4.14$)$ \\
\hline Renal disease (as per Quan et $a^{23}$ ), n (\%) & $136(6.4)$ & $155(0.7)$ & 9.31 (7.36 to 11.77$)$ \\
\hline Nephritis and proteinuria, $\mathrm{n}(\%)$ & $346(16.4)$ & $112(0.5)$ & 35.75 (29.54 to 45.73$)$ \\
\hline Malignancy, n (\%) & $122(5.8)$ & $1569(7.4)$ & $0.76(0.63$ to 0.92$)$ \\
\hline Patient had a metastatic solid tumour, n (\%) & $24(1.1)$ & $468(2.2)$ & $0.51(0.34$ to 0.77$)$ \\
\hline
\end{tabular}


Table 1 Continued

\begin{tabular}{|c|c|c|c|}
\hline & SLE & Comparators & OR $(95 \% \mathrm{Cl})$ \\
\hline Charlson Comorbidity Index (CCl), any item, n (\%) & $886(42)$ & $4322(20.5)$ & 2.81 (2.56 to 3.08$)$ \\
\hline 0 items, $\mathrm{n}(\%)$ & $1225(58.0)$ & $16788(79.5)$ & Reference \\
\hline $1-2$ items, n (\%) & $716(33.9)$ & 3750 (17.8) & 2.62 (2.37 to 2.89$)$ \\
\hline \multicolumn{4}{|l|}{ Hospitalisations for other rheumatic disease conditions } \\
\hline Rheumatoid arthritis, n (\%) & $149(7.1)$ & $0(0.0)$ & - \\
\hline Polymyalgia rheumatica, n (\%) & $102(4.8)$ & $0(0.0)$ & - \\
\hline Sicca symptoms, n (\%) & $49(2.3)$ & $0(0.0)$ & - \\
\hline Scleroderma, n (\%) & $23(1.1)$ & $0(0.0)$ & - \\
\hline Gout, n (\%) & $36(1.7)$ & $0(0.0)$ & - \\
\hline Other connective tissue diseases, n (\%) & $82(3.9)$ & $0(0.0)$ & - \\
\hline \multicolumn{4}{|l|}{ Medication use } \\
\hline IV/IM steroids, n (\%) & $246(11.7)$ & $197(0.9)$ & $14.00(11.54$ to 16.99$)$ \\
\hline Adverse reaction to IV/IM steroids, n (\%) & $0(0.0)$ & $<5(1.0)$ & - \\
\hline \multicolumn{4}{|c|}{$\begin{array}{l}\text { Bolded cells were statistically significantly different between patients with SLE and comparators. } \\
\text { " }<5 \text { " displayed to maintain participant confidentiality } \\
\text { IV/IM, intravenous/intramuscular. }\end{array}$} \\
\hline
\end{tabular}

(SMR 2.29, 95\% CI 2.12 to 2.47; $\mathrm{p}<0.001$ ) (figure 2B) as well as an increased 5-year rolling SMR. Compared with the general population, a hospitalisation for SLE associated with an increased SMR at 1 year, 1-5 years, 5-10 years, $10-15$ years and $>15$ years post-hospitalisation (online supplemental table 4).

\section{Underlying and contributing causes of death in patients hospitalised for SLE compared with general population comparators}

Competing risks regression models determined the relative contribution of conditions captured on the death certificate between those with a hospitalisation for SLE and comparators. A hospitalisation for SLE associated with an increased risk of death from infection (aHR 4.38), cardiovascular disease (aHR 2.09), cerebrovascular disease (aHR 1.39), peripheral vascular disease (aHR

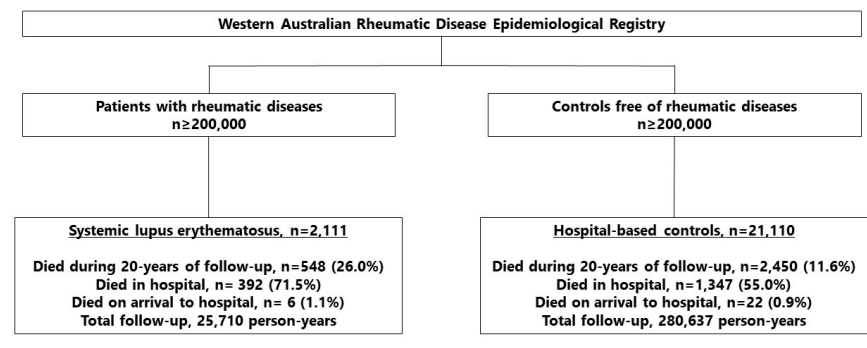

Figure 1 Study flowchart.
2.64), respiratory disease (aHR 2.26), renal disease (aHR 3.42 ), and gastrointestinal and/or hepatic disease (aHR 2.27). In addition, SLE increased the risk of mortality related to malignancies of the lymphatic and hematopoietic tissues (aHR 1.91); cytopenias, including anaemia (aHR 5,83), haemolytic anaemia and thrombocytopenia; as well as neurological disease, endocrine and metabolic diseases (excluding diabetes), skin and subcutaneous disease, and mental health and behavioural disorders, including intentional self-harm (table 4).

\section{DISCUSSION}

This population-level longitudinal cohort study from Western Australia demonstrated that an index hospitalisation in patients with SLE was independently associated with an increased (aHR 2.03) risk of premature mortality, compared with matched general population comparators over the 35 years since 1980 . The risk of mortality was highest within 5 years of hospitalisation, with younger patients $(<40$ years of age), socioeconomically disadvantaged and Aboriginal Australians being particularly vulnerable. Prevalent thromboembolic disease, harmful alcohol use, smoking, hypothyroidism, hypertension, dyslipidaemia and requirement of IV/IM corticosteroids were found to be effect modifiers of the association between a hospitalisation for SLE and premature 
Table 2 All-cause mortality, stratified by demographics, study period and time since study entry

\begin{tabular}{|c|c|c|c|c|c|c|}
\hline \multicolumn{3}{|c|}{ SLE } & \multicolumn{2}{|c|}{ Controls } & \multirow[b]{2}{*}{ HR (95\% Cl) } & \multirow[b]{2}{*}{ Adjusted HR (95\% Cl) } \\
\hline & $\mathbf{N}$ & py & $\mathbf{N}$ & py & & \\
\hline Overall & 548 & 25710 & 2450 & 280637 & $2.42(2.20$ to 2.65$)$ & $2.03(1.84$ to 2.23$)$ * \\
\hline 1980-1999 & 236 & 9045 & 781 & 113450 & 3.62 (3.13 to 4.19$)$ & $1.42(1.20$ to 1.70$) \dagger$ \\
\hline 2000-2014 & 312 & 16663 & 1669 & 167157 & 1.88 (1.67 to 2.12$)$ & $1.27(1.11$ to 1.45$) \dagger$ \\
\hline Males & 126 & 3471 & 642 & 42568 & 2.37 (1.96 to 2.87$)$ & $1.88(1.54$ to 2.29$) \dagger$ \\
\hline 1980-1999 & 55 & 1290 & 237 & 17324 & $2.90(2.16$ to 3.90$)$ & $1.07(0.76$ to 1.51$) \dagger$ \\
\hline 2000-2014 & 71 & 2180 & 405 & 24240 & $2.02(1.57$ to 2.60$)$ & $1.37(1.04$ to 1.81$) \dagger$ \\
\hline Females & 422 & 22239 & 1808 & 238068 & 2.48 (2.23 to 2.76$)$ & $2.11(1.89$ to 2.35$) \dagger$ \\
\hline 1980-1999 & 181 & 7754 & 544 & 96126 & 3.97 (3.36 to 4.70$)$ & $1.60(1.30$ to 1.96$) \dagger$ \\
\hline 2000-2014 & 241 & 14482 & 1267 & 141917 & 1.88 (1.63 to 2.15$)$ & $1.26(1.08 .1 .47) \dagger$ \\
\hline Non-Indigenous & 494 & 24018 & 2231 & 263126 & 2.41 (2.18 to 2.66 ) & $1.99(1.80$ to 2.21$) \dagger$ \\
\hline 1980-1999 & 213 & 8545 & 711 & 105208 & 3.55 (3.04 to 4.13$)$ & $1.40(1.17$ to 1.69$) \dagger$ \\
\hline 2000-2014 & 281 & 15470 & 1520 & 157890 & 1.89 (1.67 to 2.15$)$ & $1.26(1.09$ to 1.45$) \dagger$ \\
\hline Indigenous Australians & 54 & 1691 & 219 & 17511 & 2.40 (1.78 to 3.23$)$ & 3.32 (2.45 to 4.49$) \ddagger$ \\
\hline 1980-1999 & 23 & 499 & 70 & 8242 & 4.65 (2.88 to 7.49$)$ & 4.65 (2.87 to 7.52$)^{\S}$ \\
\hline 2000-2014 & 31 & 1192 & 149 & 9267 & 1.63 (1.11 to 2.40$)$ & $2.63(1.78$ to 3.90$) \S$ \\
\hline \multicolumn{7}{|l|}{ Age groups } \\
\hline$<40$ & 89 & 13175 & 91 & 166209 & 12.09 (9.02 to 16.20$)$ & $7.46(5.41$ to 10.28$) \dagger$ \\
\hline $40-50$ & 64 & 5182 & 100 & 39560 & 4.95 (3.62 to 6.78 ) & $2.83(2.02$ to 3.97$) \dagger$ \\
\hline $50-60$ & 104 & 3480 & 221 & 30105 & 4.05 (3.21 to 5.12) & $2.57(2.00$ to 3.29$) \dagger$ \\
\hline $60-70$ & 132 & 2385 & 620 & 24519 & 2.21 (1.83 to 2.67$)$ & $1.82(1.50$ to 2.20$) \dagger$ \\
\hline$\geq 70$ & 159 & 1489 & 1418 & 20244 & 1.49 (1.26 to 1.75$)$ & $1.23(1.04$ to 1.46$) \dagger$ \\
\hline \multicolumn{7}{|l|}{ Socioeconomic status \# } \\
\hline Quintile 1 & 32 & 2678 & 149 & 27223 & 2.17 (1.48 to 3.18$)$ & $2.49(1.67$ to 3.73$) \dagger$ \\
\hline Quintile 2 & 28 & 2644 & 159 & 31691 & $2.13(1.43$ to 3.19$)$ & $1.79(1.17$ to 2.76$) \dagger$ \\
\hline Quintile 3 & 35 & 3451 & 186 & 38974 & 2.14 (1.49 to 3.07 ) & 1.62 (1.09 to 2.42$) \dagger$ \\
\hline Quintile 4 & 56 & 6188 & 359 & 65195 & 1.66 (1.25 to 2.19$)$ & $1.60(1.19$ to 2.16$) \dagger$ \\
\hline Quintile 5 & 81 & 5384 & 411 & 57002 & 2.11 (1.66 to 2.68$)$ & 1.87 (1.46 to 2.39$) \dagger$ \\
\hline \multicolumn{7}{|l|}{ Since study entry } \\
\hline 1 year & 111 & 2035 & 454 & 20791 & 2.48 (2.02 to 3.05$)$ & $1.63(1.32$ to 2.02$)$ * \\
\hline 3 years & 204 & 5855 & 781 & 60309 & 2.67 (2.29 to 3.12 ) & $1.85(1.57$ to 2.17$)$ * \\
\hline 5 years & 264 & 9312 & 1029 & 96490 & 2.64 (2.31 to 3.02$)$ & $1.96(1.70$ to 2.25$)$ * \\
\hline
\end{tabular}

Bolded HRs were statistically significant, $\mathrm{p}<0.05$.

*Adjusted for age $^{2}$, sex, Indigenous status, Charlson Comorbidity Index (CCl) categories, harmful alcohol consumption, obesity and smoking status.

†Adjusted for age, age 2 , sex, Indigenous status, $\mathrm{CCl}$ categories, harmful alcohol consumption, obesity and smoking status.

$\ddagger$ Adjusted for $\mathrm{age}^{2}$ and sex only.

$\S$ Adjusted for age, age $^{2}$ and sex only.

py, person-years.

mortality, and warrant further investigation. Within patients with SLE, the risk of mortality was higher with in those with (lupus) nephritis. The presence of antiphospholipid syndrome, thromboembolic disease or other rheumatic disease conditions, including rheumatoid arthritis within patients hospitalised for SLE conferred no additional mortality risk.
The age and gender distributions for patients with SLE in this study were comparable with other studies reporting on mortality in hospitalised ${ }^{1926-28}$ and community-based (population-level) patients with SLE. ${ }^{4}$ For marginal differences in sex and Aboriginality at timezero, patients with SLE had accrued three times as much the comorbidity $(\mathrm{CCI}>0)$ during a similar (9 years) lookback period 
Table 3 Effect modification between patients with SLE and hospital-based controls

\begin{tabular}{|c|c|c|c|c|c|}
\hline & \multicolumn{2}{|c|}{ Patients with SLE } & \multicolumn{2}{|c|}{ Controls } & \multirow{2}{*}{$\begin{array}{l}\text { Cox proportional hazards } \\
\text { aHR }(95 \% \mathrm{Cl}) \text { * }\end{array}$} \\
\hline & Died & Person-years & Died & Person-years & \\
\hline Prevalent thromboembolic events & 95 & 2393 & 180 & 4289 & $1.32(1.02$ to 1.71$)$ \\
\hline History of harmful alcohol use & 33 & 698 & 127 & 4413 & 1.29 (0.88 to 1.91$)$ \\
\hline No history of harmful alcohol use & 515 & 25013 & 2323 & 276224 & 2.06 (1.86 to 2.27$)$ \\
\hline History of obesity & 63 & 1277 & 118 & 5501 & 1.97 (1.41 to 2.76$)$ \\
\hline No history of obesity & 485 & 24433 & 2332 & 275136 & 2.03 (1.84 to 2.25$)$ \\
\hline Prevalent hypertension & 194 & 3836 & 713 & 14902 & $1.47(1.24$ to 1.74$)$ \\
\hline Normotensive & 354 & 21874 & 1737 & 265735 & $2.25(2.00$ to 2.54$)$ \\
\hline Normal lipid levels & 503 & 25134 & 2259 & 276326 & 2.06 (1.86 to 2.27$)$ \\
\hline Prevalent diabetes & 68 & 995 & 355 & 6467 & 1.26 (0.96 to 1.65$)$ \\
\hline Non-diabetic & 480 & 24715 & 2095 & 274170 & 2.17 (1.95 to 2.40$)$ \\
\hline IV/IM corticosteroids ever & 71 & 3420 & 30 & 2648 & 1.78 (1.13 to 2.78$)$ \\
\hline No IV/IM corticosteroids ever & 477 & 22290 & 2420 & 277988 & 1.98 (1.79 to 2.19$)$ \\
\hline
\end{tabular}

Bolded HRs were statistically significant, $p<0.05$.

*Adjusted for age, sex, Aboriginality and Charlson Comorbidity Index categories. Interaction testing, all p>0.20.

compared with general population comparators. Comorbidity accrual $(\mathrm{CCI}>0)$ in our study was similar to Kuo $e t$ $a l .^{29}$ Our overall CCI scores were higher on a per-patient level (data not shown) than those reported a population study in the UK, ${ }^{5}$ which might represent a selection bias given that our sample was hospital ascertained, and patients were on average 15 years older than the typical onset of age of SLE. Beyond the CCI items, our data confirm the higher prevalence of a range of comorbidities, including cardiovascular disease, thromboembolic disease, hypothyroidism, hypertension, osteoporosis and dyslipidaemia experienced by patients with SLE. ${ }^{30-32}$ While the Systemic Lupus International Collaborating Clinics/American College of Rheumatology (SLICC/ ACR) Damage Index (SDI) has not been validated for use in Australian administrative datasets, we think that the CCI has sufficient coverage of conditions captured in the SDI to produce robust and meaningful mortality estimates. Interestingly, the attenuation of the association between mortality in Aboriginal Australians with SLE with increasing categories of CCI suggests that a broader rather than SLE-specific comorbidity index is better suited to population-level research and the generalisability of the findings, especially when discussing the health disparities been Aboriginal and non-Aboriginal Australians. In addition, patients with SLE had higher rates of smoking, harmful alcohol consumption and obesity compared with controls. While the prevalence of smoking was similar to Jorge et al $(\sim 30 \%),{ }^{5}$ our alcohol and obesity exposures were much lower than other comparable studies. ${ }^{529}$ This most likely resulted from the identification of these exposures on discharge summaries (meaning the conditions required management during a hospitalisation), rather than from outpatient letters or primary care information systems. The latter are better suited to capture details, such as standard drinks per week, cigarettes smoked per day and accurate measures of anthropometry, including body mass index or measures of adiposity ${ }^{529}$ Furthermore, our hospitalisation-level data representing either the acute exacerbation or ongoing management of moderate-tosevere SLE would explain the attenuation of the risk of mortality in the effect modification analysis. Collectively, our findings confirm that patients hospitalised for SLE have higher accrual of comorbidity and modifiable risk factors compared with demographically and temporally matched general population comparators. Furthermore, the increased prevalence of comorbidity and modifiable risk factors in this and other studies indicates that there is significant scope for medical and allied health services to improve the health outcomes and reduce the risk of premature mortality at or before the index hospitalisation for SLE. ${ }^{33}$

Our data demonstrated that patients with SLE had increased risk of all-cause mortality (aHR 2.03, 95\% CI 1.84 to 2.23; $\mathrm{p}<0.001)$ compared with hospital-based controls, and to the general population of Western Australia (SMR 2.29, 95\% CI 2.12 to 2.47; $\mathrm{p}<0.001)$. The increased risk of mortality shown herein aligned with population-level 


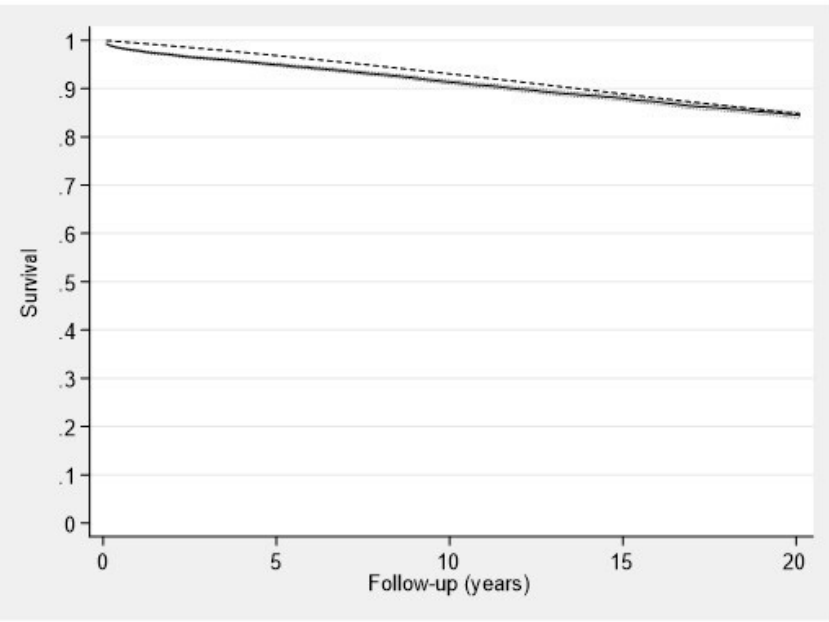

Figure 2a

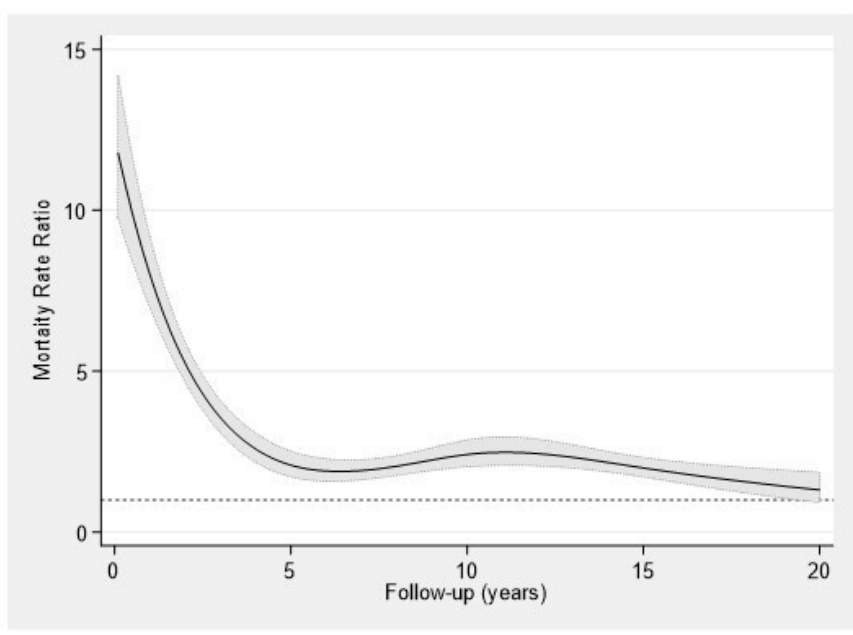

Figure $2 b$

Figure 2 (A) Comparing mortality rates of hospital-based general population comparators of the WARDER compared with the general population of Western Australia. Black line: observed survival with $95 \% \mathrm{Cl}$ (grey area) of WARDER comparators. Dotted line: expected survival of general population of Western Australia. (B) Mortality rate ratios of hospital-based patients with SLE compared with the general population of Western Australia. Black line: mortality rate ratio; grey area: $95 \% \mathrm{Cl}$ of mortality rate ratios.

findings from Hungary (aHR 2.75).$^{34}$ While our timelimited (1, 3 and 5 years since hospitalisation) findings were tempered compared with other studies (all, aHR >4), we had included more confounding variables, which may partly explain the differences between the published estimates. While our SMR (2.29) was higher than the community-based population-level data from the UK (MRR 1.67, 95\% CI 1.43 to 1.94 ), ${ }^{4}$ our estimates were lower than the meta-SMR of 3 reported in a meta-analysis of observational studies, ${ }^{35} 29$ although our 5-year SMR from 1980 to 2015 was similar to previously published estimates. Ultimately, hospitalisation for SLE conferred an increased risk of mortality for up to 20 years when compared with general population comparators, and the background population of Western Australia. ${ }^{5} 293435$

After hospitalisation for SLE, female patients had an increased risk of mortality compared with controls, and this association remained significant, although reduced in the latter 2000-2014 period. These data aligned with Rees et al (1999-2012; MRR 1.64, 95\% CI 1.43 to 1.94) who demonstrated increased mortality in female patients with SLE compared with the general population. ${ }^{4}$ We demonstrated that males with SLE had an increased risk of mortality compared with controls, which while being attenuated in the 1980-1999 period (due to a pronounced effect of CCI variable on the risk of mortality) regained significance in the 2000-2014 period (aHR $1.37,95 \%$ CI 1.04 to 1.81 ). This aligned with the ageadjusted, sex-adjusted and region-adjusted MRR for male patients with SLE $(1.80,95 \%$ CI 1.37 to 1.96 ; p $<0.001)$ of Rees et al; however, our association was weaker due to our adjustment for comorbidity and modifiable risk factors. Underwriting the attenuation of the association between a hospitalisation for SLE with mortality in males by increasing CCI categories was an increased burden of comorbidity accrual in male patients with SLE compared with women at baseline (data not shown). These data confirm similarity to the accelerated comorbidity accrual seen in males, as shown for incident CVD in the general population, ${ }^{36}$ combined with the increased prevalence of CVD risk factors shown herein and elsewhere. ${ }^{30} 32$ Taken together, our data would suggest that male and female patients with SLE have comparable mortality rates, although where differences do arise, it would most likely be related to a comorbidity effect rather than SLE-specific factors or the inherent sex bias of females with SLE. ${ }^{37-39}$

We confirmed data from cohort and population-level studies that patients with SLE died more than 10 years earlier than non-exposed controls, ${ }^{4840}$ and that patients with SLE have an increased likelihood and risk of mortality from across those $<40$ up to 70 years of age. ${ }^{41-45}$ Similar to other studies, we also demonstrated significantly (aHR 7.46) increased risk of mortality in patients with SLE under 40 years of age. ${ }^{4}$ However, we also demonstrated that patients with SLE exhibit a bimodal pattern of mortality (figure 2B), in which early deaths relate to active ('flaring') disease and/or the higher incidence of infection, and later deaths related to increased atherosclerotic CVD, side effects of long-term treatment and comorbidity. ${ }^{46}$

The Aboriginal population of Western Australia is approximately 3\%; both Aboriginal Australians with $(7.8 \%)$ and without SLE (6.0\%) were over-represented in our study. The increased prevalence of SLE in Aboriginal Australians aligns with earlier reports of a twofold higher prevalence of SLE in Aboriginal Australians compared with non-Aboriginal Australian cohorts. ${ }^{78} 47$ Overall, Aboriginal patients with SLE had the highest age-adjusted and sex-adjusted risk of mortality (aHR 3.32). Yet the risk of mortality in non-Aboriginal Australians with SLE was similar to other studies. ${ }^{48}$ Our data mirror the literature, 
Table 4 Competing risks analysis of the association between a hospitalisation for SLE with causes of death from 1980 to 2014

\begin{tabular}{|c|c|c|c|}
\hline & \multirow{2}{*}{$\begin{array}{l}\text { SLE } \\
\mathrm{n}=2111\end{array}$} & \multirow{2}{*}{$\begin{array}{l}\text { Hospital-based controls } \\
\mathrm{n}=21110\end{array}$} & \multirow{2}{*}{$\begin{array}{l}\text { Adjusted HR } \\
(95 \% \mathrm{Cl})\end{array}$} \\
\hline & & & \\
\hline Certain infectious and parasitic diseases (A00-B99) & $67(3.2)$ & $128(0.6)$ & 4.38 (3.15 to 6.09$)$ \\
\hline Septicaemia & $48(2.3)$ & $102(0.5)$ & 3.95 (2.72 to 5.73$)$ \\
\hline Influenza and/or pneumonia (J00-J18) & $49(2.3)$ & $225(1.1)$ & $2.16(1.57$ to 2.97$)$ \\
\hline Malignancy (C00-C97) & $121(5.7)$ & $897(4.2)$ & $0.94(0.76$ to 1.15$)$ \\
\hline Digestive tract & $27(1.3)$ & $263(1.2)$ & $0.76(0.50$ to 1.15$)$ \\
\hline Lung cancer & $28(1.3)$ & $172(0.8)$ & 1.27 (0.84 to 1.95$)$ \\
\hline Lymphatic and hematopoietic tissues & $17(0.8)$ & $76(.4)$ & 1.91 (1.10 to 3.31$)$ \\
\hline Breast & $12(0.6)$ & $100(0.5)$ & 0.71 (0.38 to 1.31$)$ \\
\hline Skin cancer or melanoma & $4(0.2)$ & $25(0.1)$ & $1.07(0.36$ to 3.17$)$ \\
\hline Central nervous system & $4(0.2)$ & $31(0.1)$ & $0.94(0.32$ to 2.78$)$ \\
\hline Benign neoplasms (D00-D49) & $8(0.4)$ & $28(0.1)$ & 2.54 (1.21 to 5.36$)$ \\
\hline $\begin{array}{l}\text { Blood, blood-forming organs and/or immune related } \\
\text { (D50-D89) }\end{array}$ & $44(2.1)$ & $56(.3)$ & $6.47(4.28$ to 9.77$)$ \\
\hline Anaemias & $21(1.0)$ & $33(.2)$ & 5.83 (3.39 to 10.04$)$ \\
\hline Endocrine, nutritional and metabolic diseases (E00-E90) & $72(3.4)$ & $307(1.5)$ & 1.67 (1.27 to 2.20$)$ \\
\hline Diabetes & $41(1.9)$ & $213(1.0)$ & $1.20(0.85$ to 1.69$)$ \\
\hline Mental and behavioural disorders (F00-F99) & $39(1.8)$ & $280(1.3)$ & $1.42(1.01$ to 2.01$)$ \\
\hline Substance abuse disorders & $13(0.6)$ & $67(0.3)$ & 1.74 (0.94 to 3.22$)$ \\
\hline Intentional self-harm & $6(0.3)$ & $11(0.1)$ & 5.39 (1.90 to 15.28$)$ \\
\hline Diseases of the nervous system (G00-G99) & $38(1.8)$ & $208(1.0)$ & 1.75 (1.23 to 2.49$)$ \\
\hline Dementia & $23(1.1)$ & $278(1.3)$ & $0.89(0.57$ to 1.37$)$ \\
\hline Parkinson's & $3(.1)$ & $30(.1)$ & $1.11(0.33$ to 3.80$)$ \\
\hline Cardiovascular disease (100-199) & $268(12.7)$ & $1231(5.8)$ & 2.09 (1.79 to 2.45$)$ \\
\hline Congestive heart disease & $116(5.5)$ & $604(2.9)$ & 1.80 (1.45 to 2.23$)$ \\
\hline Hypertensive disease & $71(3.4)$ & $398(1.9)$ & 1.78 (1.36 to 2.32$)$ \\
\hline Heart failure & $64(3.0)$ & $244(1.2)$ & 2.47 (1.85 to 3.29$)$ \\
\hline Cerebrovascular disease & $53(2.5)$ & $349(1.7)$ & 1.39 (1.03 to 1.87$)$ \\
\hline Vascular disease & $35(1.7)$ & $108(0.5)$ & 2.64 (1.78 to 3.91$)$ \\
\hline Arrhythmias & $19(0.9)$ & $159(0.8)$ & $1.12(0.69$ to 1.83$)$ \\
\hline Respiratory system (J00-J99) & $139(6.6)$ & $571(2.7)$ & 2.26 (1.85 to 2.76$)$ \\
\hline Chronic pulmonary disease & $46(2.2)$ & $225(1.1)$ & $1.74(1.26$ to 2.40$)$ \\
\hline Respiratory failure & $26(1.2)$ & $106(0.5)$ & 2.08 (1.33 to 3.25$)$ \\
\hline Diseases of the digestive system (K00-K93) & $57(2.7)$ & $200(0.9)$ & 2.27 (1.67 to 3.08$)$ \\
\hline Chronic liver disease & $23(1.1)$ & $58(0.3)$ & 2.56 (1.53 to 4.29$)$ \\
\hline Gastrointestinal bleeding & $7(0.3)$ & $47(0.2)$ & $1.31(0.59$ to 2.94$)$ \\
\hline Diseases of the skin and subcutaneous system (L00-L99) & $17(0.8)$ & $22(0.1)$ & 7.74 (3.93 to 15.25$)$ \\
\hline $\begin{array}{l}\text { Musculoskeletal, connective tissue and subcutaneous } \\
\text { diseases (M00-M99) }\end{array}$ & $168(8.0)$ & $37(0.2)$ & - \\
\hline SLE & $135(6.4)$ & $0(0.0)$ & - \\
\hline Diseases of the genitourinary system (NO0-N99) & $87(4.1)$ & $227(1.1)$ & $3.43(2.64$ to 4.46$)$ \\
\hline Renal failure & $71(3.4)$ & $186(0.9)$ & 3.39 (2.54 to 4.51$)$ \\
\hline Renal or urinary tract infection & $16(0.8)$ & $31(0.1)$ & $5.20(2.85$ to 9.50$)$ \\
\hline
\end{tabular}

Competing risks Cox proportional HRs adjusted for age, sex, Aboriginality and Charlson Comorbidity Index $(\mathrm{CCl}) \mathrm{categories}(\mathrm{CCl}=0$, $\mathrm{CCl}=1-$ 2 or $\mathrm{CCl}>2$ ). 
which indicates that ethnicity is an important determinant of SLE prevalence, severity and survival. ${ }^{49}$ We showed that Aboriginal Australians remained the most vulnerable group in the 2000-2014 period (aHR 2.63). However, the association between a hospitalisation and mortality in Aboriginal Australians was attenuated in the fully adjusted model (data not shown). This finding mirrored the Australian Institute of Health and Welfare's data which showed that Aboriginal Australians die much earlier than non-Aboriginal Australians (MR 1.60), ${ }^{50}$ and aligns with the long-established mortality gap between Aboriginal and non-Aboriginal Australians. ${ }^{51} 52$ While there are some differences between Aboriginal and nonAboriginal patients with SLE with respect to the increased prevalence of anti-Smith autoantibodies, ${ }^{8} 11$ lupus nephritis ${ }^{79}$ and cytopenias ${ }^{8}$ as well as treatment-related factors (non-adherence or non-compliance), ${ }^{53}$ environmental factors, such as ultraviolet radiation exposure (nationwide), and the prevalence of infection in remote or subtropical Northern regions, ${ }^{747}$ SLE was found to be an independent risk factor for mortality herein. Our findings suggest that accrual of comorbidity and modifiable risk factors are still the strongest determinants of premature mortality in Aboriginal Australians, beyond that of SLE.

We found that a hospitalisation for SLE increased the risk of mortality across all levels of socioeconomic status, with the highest risk in the most disadvantaged group (aHR 2.49). This finding confirms that survival in patients with SLE is impacted by low socioeconomic status, especially for ethnic minorities, such as African Americans. ${ }^{54}$ The relative high risk of mortality across all SEIFA quintiles may reflect the composition of the IRSAD index, which takes into account household income, internet access, highest educational attainment, family status, unemployment, profession type (labour/managerial/ professional), disability, cost of living and asset ownership (cars/home/rental properties). Taken together, a hospitalisation for SLE affects survival across all strata of society, with the most disadvantaged being the most vulnerable.

While patients with SLE are at increased risk of many comorbidities, we showed that prevalent rheumatic diseases occurred in $10.0 \%$ at timezero. This is lower than the 38\% (n=229/600) reported by Lockshin et al data which included anti-phospholipid syndrome, rheumatoid arthritis, Sjögren's, thyroid disease and other rheumatic diseases. Within patients with SLE, we found that those with another rheumatic disease did not influence the risk of mortality. While the data on the outcomes of patients with SLE with another (overlapping) autoimmune condition are scarce, these fit with the data showing that the mortality risk is still higher in patients with $\mathrm{SLE}^{55}$ or patients with SLE-like features, ${ }^{56}$ rather than other rheumatic diseases, such as rheumatoid arthritis, which has seen improved survival over time. ${ }^{57}$ In addition, we found that patients with SLE with prevalent (lupus) nephritis, proteinuria and haematuria were at increased risk of mortality, which fits with the literature and highlights the long known concerns for renal involvement in SLE. ${ }^{58}$ Furthermore, we found no difference in the mortality risk after a hospitalisation for SLE in those with antiphospholipid syndrome (APS) or prevalent thromboembolic events. Frodlund $e t a l$ 's study showed that prevalent APS was linked to damage accrual. ${ }^{59}$ We found that prevalent thromboembolic events (of which APS was prevalent in $>30 \%$ ) attenuated (was an effect modifier of) the association between a hospitalisation for SLE and mortality, which signifies that thromboembolic events influence survival. Taken together, this suggests that well-controlled APS may not increase the risk of mortality in patients with SLE in the absence of a clinical event. However, further studies are needed to determine the association between APS (substantiated with laboratory findings) and clinical thromboembolic events with premature mortality in patients with SLE.

With respect to the causes of death, we found that patients with SLE did not experience an increased risk of cancer-related deaths, which aligns with Yurkovich $e$ al (meta-SMR 1.19, 95\% CI 0.89 to 1.59). ${ }^{3}$ However, we found that patients with SLE had increased risk of mortality with malignancies of the lymphatic and hematopoietic tissues, which aligned with the literature about the increased risk of lymphoma in patients with autoimmune disease. ${ }^{6061}$ Our data confirmed the increased likelihood and risk of a range of underlying causes of mortality in patients with SLE, in particular, infection, cardiovascular (CVD), respiratory ${ }^{62}$ and genitourinary (renal) diseases. ${ }^{3}$ In addition, patients with SLE had increased risk of mortality with leucopenia, thrombocytopenia and anaemias of chronic disease. ${ }^{63}$ This fits with the data on the association of thrombocytopenia in SLE being associated with a worse prognosis and premature mortality. ${ }^{64}$ Furthermore, we confirm the limited data which suggest that patients with SLE had increased likelihood and risk of mortality related to gastrointestinal disease ${ }^{65}$ hepatic disease, thyroid disorders, mental and behavioural disorders, ${ }^{66}{ }^{67}$ neurological diseases $^{68}$ and osteoporosis. ${ }^{69}$ Collectively, this demonstrates that patients with SLE have a higher burden of a wide range of comorbidities at the time of death.

The limitations of this study pertain to the identification of patients with SLE who required hospital services, that is, emergency department presentations and hospital admissions; this meant that we might not have captured those milder SLE cases who may have been managed in the community, outpatient or private practice settings, respectively. Furthermore, we were not able to ascertain whether our patients with SLE met classification criteria due to the lack laboratory data captured in the HMDC. However, this should not be considered a major issue as another study showed that only a small number of patients with SLE went without hospitalisation over an 11-year period $(6.2 \%, \mathrm{n}=19 / 309) .{ }^{20}$ Despite this potential selection bias, our mortality estimates were similar to a range of clinical, cohort and registry-based studies, and, despite the different healthcare settings, we produced nearly identical estimates 
to those from a primary care setting. ${ }^{45}$ The relative strength and stability of our estimates are ensured by the ability to identify a large number of patients with SLE during a 35-year period, which allowed for an average of 9 years of lookback and 14 years of follow-up. Our SLE cohort of 2111 in the context of an average population of 2.1 million in Western Australia over the study period approximates the 1:1000 prevalence reported in other studies. ${ }^{70}$ In addition, we ascertained complete mortality data from the WA Death Registry, which captures all death events in the state, ensuring that we accurately identified this outcome for all patients.

In conclusion, hospital-ascertained patients with SLE were at an increased risk of all-cause and cause-specific mortality compared with hospital-based controls and the general population of WA from 1980 to 2014. The risk of death was especially high for younger patients with SLE $(<40$ years of age), socioeconomically disadvantaged, Aboriginal Australians and those with prevalent nephritis. Critically, our findings show that for moderateto-severe SLE, the risk of premature mortality remained throughout the 2000 to 2014 period.

\section{Author affiliations}

${ }^{1}$ Rheumatology Section, School of Medicine, University of Western Australia Faculty of Medicine Dentistry and Health Sciences, Crawley, Western Australia, Australia

${ }^{2}$ Rheumatology Unit, The Queen Elizabeth Hospital, Woodville South, South Australia, Australia

${ }^{3}$ School of Population \& Global Health, The University of Western Australia Faculty of Medicine Dentistry and Health Sciences, Perth, Western Australia, Australia ${ }^{4}$ Rheumatology, Fiona Stanley Hospital, Murdoch, Western Australia, Australia ${ }^{5}$ Rheumatology, Sir Charles Gairdner \& Osborne Park Healthcare Group, Nedlands, Western Australia, Australia

Acknowledgements The authors wish to thank the staff at the Western Australian Data Linkage Branch and Emergency Department Data Collection, Hospital Morbidity Data Collection, Western Australian Cancer Registry, and Death Registrations.

Contributors The guarantor (WDR) accepts full responsibility for the work and/ or the conduct of the study, had access to the data, takes responsibility for the integrity and accuracy of the data analysis, and controlled the decision to publish. All authors contributed to and are responsible for the content and writing of the paper.

Funding This work was supported by an unrestricted grant from the Arthritis and Osteoporosis Foundation of Western Australia (JCN) and Arthritis Australia (WDR, DP, HIK and JCN received an unrestricted Australian Project Grant). WDR received a PhD Scholarship in Memory of John Donald Stewart, the Gabrielle Vitale Memorial Fund Grant from the Lupus Group of Western Australia, and the Australian Rheumatology Association (Western Australia branch) Research \& Training Scholarship.

Competing interests None declared.

Patient consent for publication Not applicable.

Ethics approval This study was approved by the WA Health HREC approval no. 2016/24.

Provenance and peer review Not commissioned; externally peer reviewed. Data availability statement No data are available. All data relevant to the study are included in the article or uploaded as online supplemental information. Not applicable.

Supplemental material This content has been supplied by the author(s). It has not been vetted by BMJ Publishing Group Limited (BMJ) and may not have been peer-reviewed. Any opinions or recommendations discussed are solely those of the author(s) and are not endorsed by BMJ. BMJ disclaims all liability and responsibility arising from any reliance placed on the content. Where the content includes any translated material, BMJ does not warrant the accuracy and reliability of the translations (including but not limited to local regulations, clinical guidelines, terminology, drug names and drug dosages), and is not responsible for any error and/or omissions arising from translation and adaptation or otherwise.

Open access This is an open access article distributed in accordance with the Creative Commons Attribution Non Commercial (CC BY-NC 4.0) license, which permits others to distribute, remix, adapt, build upon this work non-commercially, and license their derivative works on different terms, provided the original work is properly cited, appropriate credit is given, any changes made indicated, and the use is non-commercial. See: http://creativecommons.org/licenses/by-nc/4.0/.

\section{ORCID iDs}

Warren David Raymond http://orcid.org/0000-0002-2537-0070

Johannes Cornelis Nossent http://orcid.org/0000-0002-2833-7997

\section{REFERENCES}

1 Kasitanon N, Magder LS, Petri M. Predictors of survival in systemic lupus erythematosus. Medicine 2006;85:147-56.

2 Bernatsky S, Boivin J-F, Joseph L, et al. Mortality in systemic lupus erythematosus. Arthritis Rheum 2006;54:2550-7.

3 Yurkovich M, Vostretsova K, Chen W, et al. Overall and causespecific mortality in patients with systemic lupus erythematosus: a meta-analysis of observational studies. Arthritis Care Res 2014;66:608-16.

4 Rees F, Doherty M, Grainge MJ, et al. Mortality in systemic lupus erythematosus in the United Kingdom 1999-2012. Rheumatology 2016;55:854-60.

5 Jorge AM, Lu N, Zhang Y, et al. Unchanging premature mortality trends in systemic lupus erythematosus: a general population-based study (1999-2014). Rheumatology 2018;57:337-44.

6 Boers A, Li Q, Wong M, et al. Differences in SLE disease activity between patients of Caucasian and south-east Asian/ Chinese background in an Australian hospital. APLAR Journal of Rheumatology 2006;9:43-8.

7 Bossingham D. Systemic lupus erythematosus in the far north of Queensland. Lupus 2003;12:327-31.

8 Segasothy M, Phillips PA. Systemic lupus erythematosus in Aborigines and Caucasians in central Australia: a comparative study. Lupus 2001;10:439-44.

9 Nossent J, Raymond W, Kang A, et al. The current role for clinical and renal histological findings as predictor for outcome in Australian patients with lupus nephritis. Lupus 2018;27:961203318792361.

10 Bloor G, Rigby RJ, Richmond JM. Systemic lupus erythematosus in Australia aborigines. Aust N Z J Med 1982;12:8.

11 Anstey NM, Bastian I, Dunckley H, et al. Systemic lupus erythematosus in Australian aborigines: high prevalence, morbidity and mortality. Aust N Z J Med 1993;23:646-51.

12 Holman CD, Bass AJ, Rouse IL, et al. Population-based linkage of health records in Western Australia: development of a health services research linked database. Aust N Z J Public Health 1999;23:453-9.

13 World Health Organization \& International Conference for the Ninth Revision of the International Classification of Diseases. Manual of the international statistical classification of diseases, injuries, and causes of death: based on the recommendations of the ninth revision conference, 1975, and adopted by the Twenty-ninth World Health Assembly. 1975 revision. Geneva: World Health Organization, 1977.

14 Centre NC. The Australian version of the International Classification of Diseases, 9th revision, Clinical Modification (ICD-9-CM). Sydney: National Coding Centre, 1996.

15 National Centre for Classification in Health. The International Statistical Classification of Diseases and Related Health Problems, 10th revision, Australian Modification (ICD-10-AM). Sydney: National Centre for Classification in Health, Faculty of Health Sciences, University of Sydney, 1998.

16 Australian coding standards for ICD-10-AM and ACHI 2013.

17 Ward MM. Estimating disease prevalence and incidence using administrative data: some assembly required. J Rheumatol 2013;40:1241-3.

18 Moores KG, Sathe NA. A systematic review of validated methods for identifying systemic lupus erythematosus (SLE) using administrative or claims data. Vaccine 2013;31 Suppl 10:K62-73.

19 Rodríguez Montero S, Martínez R, Marenco J. Hospitalisation of individuals with systemic lupus erythematosus: an analysis of 84 patients. Ann Rheum Dis 2011;70:A83-4.

20 Rosa GPda, Ortega MF, Teixeira A, et al. Causes and factors related to hospitalizations in patients with systemic lupus erythematosus: analysis of a 20-year period (1995-2015) from a single referral centre in Catalonia. Lupus 2019;28:1158-66. 
21 Australian Bureau of Statistics (Brian Pink). Technical Paper - SocioEconomic Indexes for Areas (SEIFA). Australian Bureau of Statistics, 2011.

22 Australian Institute of Health and Welfare. Multiple causes of death: an analysis of all natural and selected chronic disease causes of death 1997-2007. Canberra: AlHW, 2012.

23 Quan $\mathrm{H}$, Li B, Couris CM, et al. Updating and validating the Charlson comorbidity index and score for risk adjustment in hospital discharge Abstracts using data from 6 countries. Am J Epidemiol 2011;173:676-82.

24 Australian Bureau of Statistics. Australian Demographic Statistics Estimated Resident Population, Western Australia (2011), 2012.

25 Dickman PW, Coviello E. Estimating and modeling relative survival. Stata J 2015;15:186-215.

26 Lee J, Dhillon N, Pope J. All-cause hospitalizations in systemic lupus erythematosus from a large Canadian referral centre. Rheumatology 2013;52:905-9.

27 Edwards CJ, Lian TY, Badsha H, et al. Hospitalization of individuals with systemic lupus erythematosus: characteristics and predictors of outcome. Lupus 2003;12:672-6.

28 Feng X, Pan W, Liu L, et al. Prognosis for hospitalized patients with systemic lupus erythematosus in China: 5-year update of the Jiangsu cohort. PLoS One 2016;11:e0168619.

29 Kuo C-F, Chou I-J, Rees F, et al. Temporal relationships between systemic lupus erythematosus and comorbidities. Rheumatology 2019;58:840-8

30 Munguia-Realpozo P, Mendoza-Pinto C, Sierra Benito C, et al. Systemic lupus erythematosus and hypertension. Autoimmun Rev 2019:18:102371.

31 Sen D, Keen RW. Osteoporosis in systemic lupus erythematosus: prevention and treatment. Lupus 2001;10:227-32.

32 Tselios K, Koumaras C, Gladman DD, et al. Dyslipidemia in systemic lupus erythematosus: just another comorbidity? Semin Arthritis Rheum 2016:45:604-10.

33 Chakravarty EF, Bush TM, Manzi S, et al. Prevalence of adult systemic lupus erythematosus in California and Pennsylvania in 2000: estimates obtained using hospitalization data. Arthritis Rheum 2007;56:2092-4.

34 Kedves M, Kósa F, Kunovszki P, et al. Large-scale mortality gap between SLE and control population is associated with increased infection-related mortality in lupus. Rheumatology 2020:59:3443-51.

35 Pincus T, Gibson KA, Block JA. Premature mortality: a neglected outcome in rheumatic diseases? Arthritis Care Res 2015;67:1043-6.

36 Leening MJG, Ferket BS, Steyerberg EW, et al. Sex differences in lifetime risk and first manifestation of cardiovascular disease: prospective population based cohort study. BMJ 2014;349:95992.

37 Murphy G, Isenberg D. Effect of gender on clinical presentation in systemic lupus erythematosus. Rheumatology 2013;52:2108-15

38 Mok CC, To CH, Ho LY, et al. Incidence and mortality of systemic lupus erythematosus in a southern Chinese population, 2000-2006. $J$ Rheumatol 2008;35:1978-82.

39 Lee YH, Choi SJ, Ji JD, et al. Overall and cause-specific mortality in systemic lupus erythematosus: an updated meta-analysis. Lupus 2016;25:727-34.

40 Bao L, Cunningham PN, Quigg RJ. The complement system in lupus nephritis [version 1; referees: 1 approved, 1 approved with reservations], 2015.

41 Hersh AO, Trupin L, Yazdany J, et al. Childhood-onset disease as a predictor of mortality in an adult cohort of patients with systemic lupus erythematosus. Arthritis Care Res 2010;62:1152-9.

42 Chun B-C, Bae S-C. Mortality and cancer incidence in Korean patients with systemic lupus erythematosus: results from the Hanyang lupus cohort in Seoul, Korea. Lupus 2005;14:635-8.

43 Jacobsen S, Petersen J, Ullman S, et al. Mortality and causes of death of 513 Danish patients with systemic lupus erythematosus. Scand J Rheumatol 1999;28:75-80.

44 Moss KE, loannou Y, Sultan SM, et al. Outcome of a cohort of 300 patients with systemic lupus erythematosus attending a dedicated clinic for over two decades. Ann Rheum Dis 2002;61:409-13.

45 Gordon MF, Stolley PD, Schinnar R. Trends in recent systemic lupus erythematosus mortality rates. Arthritis Rheum 1981;24:762-9.

46 Urowitz MB, Bookman AA, Koehler BE, et al. The bimodal mortality pattern of systemic lupus erythematosus. Am J Med $1976: 60: 221-5$
47 Grennan DM, Bossingham D. Systemic lupus erythematosus (SLE): different prevalences in different populations of Australian aboriginals. Aust N Z J Med 1995;25:182-3.

48 Gómez-Puerta JA, Barbhaiya M, Guan H, et al. Racial/ethnic variation in all-cause mortality among United States Medicaid recipients with systemic lupus erythematosus: a Hispanic and Asian paradox. Arthritis Rheumatol 2015;67:752-60.

49 Crosslin KL, Wiginton KL. The impact of race and ethnicity on disease severity in systemic lupus erythematosus. Ethn Dis 2009;19:301-7.

50 Australian Institute of Health and Welfare. The health and welfare of Australia's Aboriginal and Torres Strait Islander peoples. online: Australian Institute of Health and Welfare, 2015.

51 Phillips B, Daniels J, Woodward A, et al. Mortality trends in Australian Aboriginal peoples and New Zealand Māori. Popul Health Metr 2017;15:25

52 Hyde Z, Smith K, Flicker L, et al. Mortality in a cohort of remoteliving Aboriginal Australians and associated factors. PLoS One 2018;13:e0195030.

53 Vincent FB, Bourke P, Morand EF, et al. Focus on systemic lupus erythematosus in Indigenous Australians: towards a better understanding of autoimmune diseases. Intern Med $J$ 2013;43:227-34.

54 Sule S, Petri M. Socioeconomic status in systemic lupus erythematosus. Lupus 2006;15:720-3.

55 Tektonidou MG, Lewandowski LB, $\mathrm{Hu}$ J, et al. Survival in adults and children with systemic lupus erythematosus: a systematic review and Bayesian meta-analysis of studies from 1950 to 2016. Ann Rheum Dis 2017;76:2009-16.

56 Icen M, Nicola PJ, Maradit-Kremers H, et al. Systemic lupus erythematosus features in rheumatoid arthritis and their effect on overall mortality. J Rheumatol 2009;36:50-7.

57 Zhang Y, Lu N, Peloquin C, et al. Improved survival in rheumatoid arthritis: a general population-based cohort study. Ann Rheum Dis 2017:76:408-13.

58 Reppe Moe SE, Molberg Ø, Strøm EH, et al. Assessing the relative impact of lupus nephritis on mortality in a population-based systemic lupus erythematosus cohort. Lupus 2019;28:818-25.

59 Frodlund M, Reid S, Wetterö J, et al. The majority of Swedish systemic lupus erythematosus patients are still affected by irreversible organ impairment: factors related to damage accrual in two regional cohorts. Lupus 2019;28:1261-72.

60 Song L, Wang Y, Zhang J, et al. The risks of cancer development in systemic lupus erythematosus (SLE) patients: a systematic review and meta-analysis. Arthritis Res Ther 2018;20:270.

61 Zintzaras E, Voulgarelis M, Moutsopoulos HM. The risk of lymphoma development in autoimmune diseases: a meta-analysis. Arch Intern Med 2005;165:2337-44.

62 Keane MP, Lynch JP. Pleuropulmonary manifestations of systemic lupus erythematosus. Thorax 2000;55:159-66.

63 Ziakas PD, Giannouli S, Zintzaras E, et al. Lupus thrombocytopenia: clinical implications and prognostic significance. Ann Rheum Dis 2005:64:1366-9.

64 Jung J-H, Soh M-S, Ahn Y-H, et al. Thrombocytopenia in systemic lupus erythematosus: clinical manifestations, treatment, and prognosis in 230 patients. Medicine 2016;95:e2818-e18.

65 Pattanaik SS, Muhammed H, Chatterjee R, et al. In-hospital mortality and its predictors in a cohort of SLE from Northern India. Lupus 2020;29:1971-7.

66 Mok CC, Chan KL, Cheung EFC, et al. Suicidal ideation in patients with systemic lupus erythematosus: incidence and risk factors. Rheumatology 2014;53:714-21.

67 Fernandez H, Cevallos A, Jimbo Sotomayor R, et al. Mental disorders in systemic lupus erythematosus: a cohort study. Rheumatol Int 2019;39:1689-95.

68 Muscal E, Brey RL. Neurologic manifestations of systemic lupus erythematosus in children and adults. Neurol Clin 2010;28:61-73.

69 Bultink IEM, Lems WF. Systemic lupus erythematosus and fractures. RMD Open 2015;1:e000069.

70 Rees F, Doherty M, Grainge MJ, et al. The worldwide incidence and prevalence of systemic lupus erythematosus: a systematic review of epidemiological studies. Rheumatology 2017:56:1945-61. 